\title{
Using Coulomb Stress Changes and Seismic Spectrum Intensities Evaluation of the Seismic Hazard Potential of Meishan Earthquake in Central Taiwan
}

\author{
Boi-Yee Liao ${ }^{1, *}$, Sen $\mathrm{Xie}^{2}$, Tsung-Shun Hsieh ${ }^{3}$ \\ ${ }^{1}$ Graduate Program of Engineering Technology Management, International College, Krirk University, Bangkok, Thailand \\ ${ }^{2}$ Department of Business Administration, International College, Krirk University, Bangkok, Thailand \\ ${ }^{3}$ International College, Krirk University, Bangkok, Thailand
}

Received May 31, 2021; Revised September 22, 2021; Accepted October 17, 2021

\begin{abstract}
Cite This Paper in the following Citation Styles
(a): [1] Boi-Yee Liao, Sen Xie, Tsung-Shun Hsieh, "Using Coulomb Stress Changes and Seismic Spectrum Intensities Evaluation of the Seismic Hazard Potential of Meishan Earthquake in Central Taiwan," Civil Engineering and Architecture, Vol. 9, No. 7, pp. 2196-2204, 2021. DOI: 10.13189/cea.2021.090709.
\end{abstract}

(b): Boi-Yee Liao, Sen Xie, Tsung-Shun Hsieh (2021). Using Coulomb Stress Changes and Seismic Spectrum Intensities Evaluation of the Seismic Hazard Potential of Meishan Earthquake in Central Taiwan. Civil Engineering and Architecture, 9(7), 2196-2204. DOI: 10.13189/cea.2021.090709.

Copyright $\bigcirc 2021$ by authors, all rights reserved. Authors agree that this article remains permanently open access under the terms of the Creative Commons Attribution License 4.0 International License

\begin{abstract}
The earthquake $\left(\mathrm{M}_{\mathrm{L}} 5.2\right)$ which occurred at Chushan town, Nantou on Nov.11, 2017 resulted many aftershocks around the hypocenter of the mainshock. The coulomb stress changes ( $\triangle \mathrm{CFSs})$ by the mainshock demonstrated by most of the aftershocks located within the portions with $\triangle$ CFSs greater than 0.1 bar, revealing the aftershocks may be induced by the mainshock. After investigating the $\triangle \mathrm{CFSs}$ at different depths, the results showed most of $\triangle \mathrm{CFSs}$ with positive values under depth $15 \mathrm{~km}$ were transferred to the southeast and southwest regions. About ten days later, there were many earthquakes $\left(\mathrm{M}_{\mathrm{L}}\right.$ 5.2 3) with depth below $15 \mathrm{~km}$ clustered exactly in the southeast region. The southwest region near the Meishan fault, caused large earthquake with $\mathrm{M}_{\mathrm{L}} 7.0$ before 110 years ago. This means the Meishan fault may be triggered by the successive earthquakes near the fault. Based on the seismic spectrum intensities, the seismic hazards by the potential Meishan earthquake are estimated. The maximum seismic intensities will occur at Chushan township and the segment of freeway 3 connecting Nantou city and Chushan township may be damaged seriously. The landslides may happen again at the junctions of Nantou and Yunlin counties, where great landslides happened when Chi-Chi earthquake $\left(\mathrm{M}_{\mathrm{L}} 7.3\right)$ occurred in 1999.
\end{abstract}

Keywords Coulomb Stress Changes, Seismic Spectrum Intensity, Seismic Hazard

\section{Introduction}

A moderate-size earthquake $\left(\mathrm{M}_{\mathrm{L}} 5.2\right.$, namely Chushan event) occurred at Chushan town, Nantou on Nov. 11, 2017 and the aftershocks $\left(\mathrm{M}_{\mathrm{L}} 2.8 \sim 4.6\right)$ up to 26 happened within one day. Coincidentally, next 10 days later, there were about 30 earthquakes $\left(\mathrm{M}_{\mathrm{L}}\right.$ 3 5.2) occurred with depth greater than $15 \mathrm{~km}$ and clustered around the east-southern region of the Chushan event in following 20 days. Most people in Chushan town were scared in the month because they experienced the serious damages due to Chi-Chi earthquake $\left(\mathrm{M}_{\mathrm{L}} 7.3\right)$ which occurred on September 21, 1999. The high rapid convergence between the Philippine Sea and Eurasian plates creates numerous seismic activities in Taiwan [1]. There were many devastating earthquakes occurred and caused serious damage in central Taiwan during the past decays. Although predicting precisely the location of potential earthquake is very important to prevent the people lives from the earthquake disaster but the techniques developing so far can't carry out the goal yet. With the study of the coseismic Coulomb stress changes ( $\triangle \mathrm{CFSs}$ ), the triggered model of potential earthquake seems to have been preliminarily probed. In the previous studies, for 
example, it is well-known that when the $\triangle \mathrm{CFSsis}$ greater than 0.1 bar, a positive Coulomb stress change can trigger subsequent events[2,3]. The insights of some potential activities of large earthquakes in the future are correlated with the relationships between Coulomb stress and the triggering of earthquakes [4-7]. The mainshock-aftershock interactions were concluded in 2013, Nantou earthquakes series [8] and 2016, Meinong earthquakes [9]. Recently, $\mathrm{Li}$ et al. [10] investigated the earthquake interactions in the central Taiwan using the $\triangle \mathrm{CFS}$ effects driven from the past earthquakes $\left(M_{L} \geq 5.5\right)$ from 1900 to 2017. They found that the rupture propagation and nucleation of large earthquakes were deeply affected by the earthquakes occurred in the central Taiwan recently. Based on these findings, the nucleation of potential earthquake could be estimated theoretically by combing the $\triangle$ CFSs of the preceding earthquakes with the specific geological surroundings. In this paper, we firstly calculated $\triangle \mathrm{CFSs}$ of Chushan event to investigate the seismic activities of aftershocks of Chushan event and the subsequent events near it. Besides, the seismic zones which may be influenced by the $\triangle$ CFSs contributed by Chushan event are detected. An active fault, Meishan fault, which is close to the epicenter of Chushan earthquake, had caused Meishan earthquake $\left(M_{L} 7.0\right) 110$ years ago. The next step in this research is to assess the seismic hazards and risks of the potential earthquake in order to reduce the damages of people. In deterministic way, Liao et al. [11] and Liao [12] employed successfully the three-parameter SI system, SIa, SIv, and SId to evaluate the possible damages in central Taiwan due to a potential earthquake and the Chang-wha fault, respectively. Therefore, the same parameters extracted from the simulated seismic waveforms are applied here to evaluate the damages by the Meichan earthquake.

\section{Methodology and Data Analysis}

Many researches in seismology had used the Coulomb-stress theory to detect the relationships how the earthquakes trigger. By taking account of kinematic source model of one large earthquake and assuming an isotropic and elastic material, the contribution of one large earthquake to the stress tensor $\mathrm{s}_{\mathrm{ij}}$ at one spatial point in the material can be calculated as

$$
\mathrm{s}_{\mathrm{ij}}=2 \mu \mathrm{e}_{\mathrm{ij}}+\lambda \delta_{\mathrm{ij}} \sum_{\mathrm{k}} \mathrm{e}_{\mathrm{kk}}
$$

where $\delta_{i j}$ are the components of the identity matrix, $\mathrm{e}_{\mathrm{ij}}$ are strain tensors and $\mu, \lambda$ are Lamé parameters, respectively. Given the fault plane of an aftershock, we can calculate the change in the normal $\sigma_{\mathrm{n}}$ and shear $\tau$ stresses in that orientation and position of the fault as [13]

$$
\begin{aligned}
& \Delta \sigma_{n}=\sum_{i j} n_{i} s_{i j} n_{j} \\
& \Delta \tau=\sum_{i j} l_{i} s_{i j} n_{j}
\end{aligned}
$$

with $n_{i}$ and $l_{i}$ the components of the normal and slip vectors. Based on the Coulomb criterion, the critical value $\tau_{c}$ can be expressed as a linear function of the normal stress $\sigma_{\mathrm{n}}$,

$$
\tau_{\mathrm{c}}=\mathrm{C}-\mu \sigma_{\mathrm{n}}
$$

where $\mathrm{C}$ is the cohesion and $\mu$ is the effective fault friction coefficient. It means the shear stress $\tau$ will rupture on the fault when it surpasses the critical value $\tau_{c}$. Thus, the Coulomb failure function can be defined as [14]

$$
\Delta \mathrm{CFF}=\Delta \tau+\mu\left(\Delta \sigma_{\mathrm{n}}+\Delta \mathrm{P}\right)
$$

where $\Delta \tau$ and $\Delta \sigma_{\mathrm{n}}$ represent the shear stress change and the fault-normal stress change. $\Delta \mathrm{P}$ is the pore pressure change within the fault. Cocco and Rice [15] offered that thepore pressure change $\Delta \mathrm{P}$ under undrained conditions which the pore water is unable to drain out have been calculated as

$$
\Delta \mathrm{P}=-\mathrm{B} \frac{\Delta \sigma_{i i}}{3}
$$

where Bis the Skempton coefficient and $\Delta \sigma_{i i}$ is the stress tensor. If $\Delta \sigma_{\mathrm{n}}=\frac{\Delta \sigma_{i i}}{3}$ in the fault zone, the change in the Coulomb Stress Change, $\triangle \mathrm{CFSs}$, on the target failure plane is represented as [16]

$$
\Delta \mathrm{CFS}=\Delta \tau+\mu^{\prime} \Delta \sigma_{n}
$$

where $\Delta \tau$ is the shear stress change on the receiver plane and in the direction of fault slip, $\Delta \sigma_{n}$ is the change in normal stress, and $\mu^{\prime}\left(\mu^{\prime}=(1-\mathrm{B}) \cdot \mu\right)$ is the effective coefficient of friction. Here, we have assumed a shear modulus of $4 \times 10^{10} \mathrm{~Pa}$, a Poisson's ratio of 0.25 and a $\mu^{\prime}$ of0.4. With the corresponding position of the rupture plane, the $\triangle \mathrm{CFS}$ on the receiver plane can be computed. By the physical phenomena, an increasing Coulomb stress means a loading, pushing the fault toward brittle failure. Conversely, a decreasing Coulomb stress represents an unloading, inhibiting earthquake rupture [17]. That is the aftershocks of a mainshock and the triggered earthquake tend to locate within the area with $\triangle \mathrm{CFS}$ greater than zero.

A station at a distance $r$ from a fault with seismic moment $\mathrm{M}_{0}$, the acceleration spectrum $A(f)$ of the seismic wave at is defined as [18]

$$
\begin{gathered}
A(f)=C M_{0} S\left(f, f_{c}\right) P\left(f, f_{\max }\right) e^{(-\pi f r / Q \beta)} / r \\
C=\frac{R \cdot F \cdot P R}{4 \pi \rho \beta^{3}}
\end{gathered}
$$

where $R$ is the radiation pattern, $F$ is the free surface amplification effects, $P R$ is a constant, and $\rho$ and $\beta$ are the density and the shear wave velocity. $S\left(f, f_{c}\right)$, represented as source spectrum, which is treated as a $\omega^{-2}$ model. If the fault plane is divided into as $\mathrm{N}^{*} \mathrm{~N}$ subfaults, the seismic wave $A_{i j}(t)$ from the subfault $(i, j)$ on the fault plane can be calculated by equation (8). The seismic 
waves receiving from all the $\mathrm{N} * \mathrm{~N}$ subfaults of the fault plane to the observation station is represented as

$$
\begin{aligned}
& \operatorname{Ac}^{N S}(t)=\sum_{i=1}^{N} \sum_{j=1}^{N} A_{i j}^{N S}\left(t-t_{i j}\right) \\
& A c^{E W}(t)=\sum_{i=1}^{N} \sum_{j=1}^{N} A_{i j}^{E W}\left(t-t_{i j}\right)
\end{aligned}
$$

where $t_{i j}$ is the delayed time.

The spectral acceleration, velocity and displacement denoted as $S_{a}(\varepsilon, T), S_{v}(\varepsilon, T)$ and $S_{d}(\varepsilon, T)$. The relationships between $S_{a}(\varepsilon, T), S_{v}(\varepsilon, T)$ and $S_{d}(\varepsilon, T)$ are represented as

$$
\mathrm{S}_{\mathrm{a}}(\omega, \varepsilon)=\omega \mathrm{S}_{\mathrm{v}}(\omega, \epsilon)=\omega^{2} \mathrm{~S}_{\mathrm{d}}(\omega, \varepsilon)
$$

where the $\omega$ is angular frequency. Based on the Spectral Acceleration, Velocity (SIv) and Displacement (SId), the Seismic Spectral Intensities SIs (SIs), are defined as

$$
\begin{aligned}
& \operatorname{SIa}(\varepsilon)=\frac{1}{\mathrm{~T}_{2}-\mathrm{T}_{1}} \int_{\mathrm{T}_{1}}^{\mathrm{T}_{2}} \mathrm{~S}_{\mathrm{a}}(\varepsilon, \mathrm{T}) \mathrm{d} \mathrm{T} \\
& \operatorname{SIv}(\varepsilon)=\frac{1}{\mathrm{~T}_{4}-\mathrm{T}_{3}} \int_{\mathrm{T}_{3}}^{\mathrm{T}_{4}} \mathrm{~S}_{\mathrm{v}}(\varepsilon, \mathrm{T}) \mathrm{d} \mathrm{T} \\
& \operatorname{SId}(\varepsilon)=\frac{1}{\mathrm{~T}_{6}-\mathrm{T}_{5}} \int_{\mathrm{T}_{5}}^{\mathrm{T}_{6}} \mathrm{~S}_{\mathrm{d}}(\varepsilon, \mathrm{T}) \mathrm{dT}
\end{aligned}
$$

where the parameters $T_{1}-T_{6}$ are dependent on the size of the earthquake and height of the buildings. Generally, a typical story height is near to $2.5 \mathrm{~m}$ to $3 \mathrm{~m}$ in Taiwan. The empirical formula applied to estimate the natural period $\mathrm{T}$ of a buildings is represented as

$$
T=c \mathrm{~h}^{3 / 4}
$$

where $\mathrm{c}$ is a constant $(0.05<\mathrm{c}<0.085)$ and $\mathrm{h}$ is the height of a building with unit as meter. Thus, by equation 16 , the different integration ranges correlate to the buildings with 1-6 floors, 7-22 floors, and taller than 22 floors are 0.1, $0.6,0.6,1.6,1.6$, and 3 seconds, respectively.

\section{Results and Discussion}

On the Nov. 11, 2017, an earthquake with magnitude $\mathrm{M}_{\mathrm{L}} 5.2$ occurred at Chushan town, Nantou. Until the next day (Nov. 12, 2017), the foreshocks and subsequent earthquakes up to twenty-six occurred around the mainshock. Besides, it is interesting that there were a cluster of earthquakes (about 30 earthquakes, $\mathrm{M}_{\mathrm{L}}$ 3 5.2) with depth greater than $15 \mathrm{~km}$ occurred at southeastern region of the Chushan event during the period between Nov.21, 2017 and Nov. 31, 2017. The locations of the two earthquake clusters are so close that the $\triangle$ CFSs of Chushan event may be applied to detect the relation between the two earthquake clusters. The $\triangle \mathrm{CFSs}$ varied with different depths of the Chushan event are displayed in Figure 1. The vertical section of $\triangle \mathrm{CFSs}$ across the epicenter of the Chushan event is shown in Figure 2.
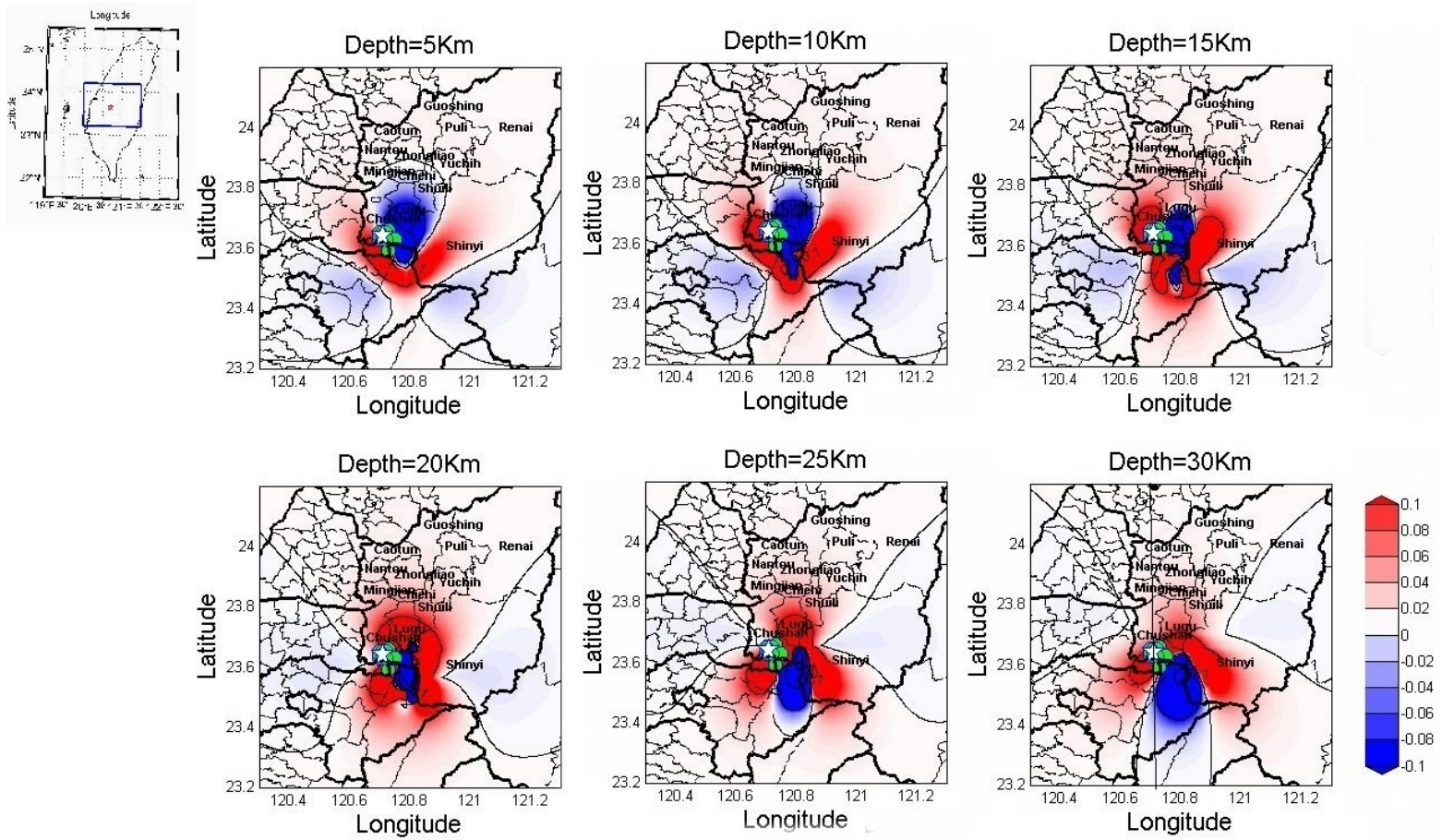

Figure 1. $\triangle$ CFSs varied with different depths from $5 \mathrm{~km}$ to $30 \mathrm{~km}$. The yellow points are the aftershocks of the mainshock. It is apparent that the aftershocks almost located within the positive $\triangle \mathrm{CFSs}$. 


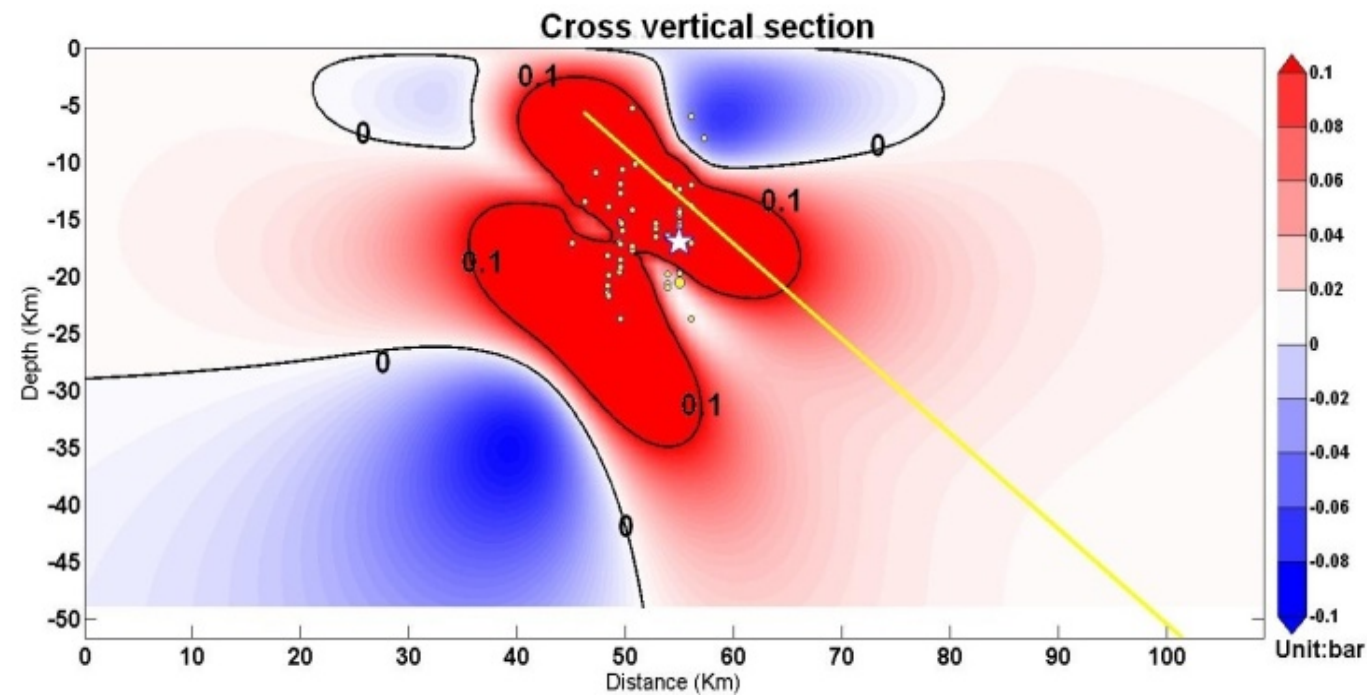

Figure 2. The vertical section of $\triangle \mathrm{CFSs}$ across the hypocenter (white star) of the Chushan event is shown. The hypocenters of the aftershocks are represented as yellow points.

In Figure 1, it can be easily observed that the almost epicenters of aftershocks locate within the positive $\Delta$ CFSs below depth $15 \mathrm{~km}$. It means the mainshock-aftershock interaction is well observed. In addition, the different patterns of $\triangle$ CFSs varied with depth have revealed the positive $\triangle$ CFSs distribute toward northeastern and northwestern directions and the negative $\triangle \mathrm{CFSs}$ focus at central part above the positive $\Delta$ CFSs at depth $5 \sim 10 \mathrm{~km}$ in Figure 1. With the depth increasing, the positive $\triangle \mathrm{CFSs}$ begin to concentrate at depth $15 \mathrm{~km}$ and change the patterns of positive $\triangle \mathrm{CFSs}$ at depth $20 \mathrm{~km}$. Finally, the positive $\Delta$ CFSs have opposite patterns distributed at depth $25 \sim 30 \mathrm{~km}$. Comparing the $\Delta$ CFSs patterns at $10 \mathrm{~km}$ with the ones at $30 \mathrm{~km}$, the $\Delta$ CFSs patterns seem to flip vertically with horizontal axis. Figure 2 is $\Delta$ CFSs distribution of the vertical section passing through the hypocenter of the mainshock. The white star is the hypocenter of the mainshock and the yellow points are the hypocenters of aftershocks. It is quite apparent that most of the aftershocks are in the positive $\triangle \mathrm{CFSs}$ area with the values greater than 0.1 bar. Sarkarinejad and Ansari [19] had pointed out aftershocks could occur in areas with high static Coulomb stress because the high $\triangle$ CFSs may add the loadings to the areas and trigger the aftershocks in these areas after the earthquake occurred. The results in this research are coincident with the studies of Sarkarinejad and Ansari. Figure 3 shows the $\triangle$ CFSs of the Chushan event and the locations of earthquakes (Table 1) with depth greater than about $15 \mathrm{~km}$ clustered at the southwestern region of the Chushan event. All of the earthquakes with depths from 15 to $30 \mathrm{~km}$ located within the positive $\Delta$ CFSs which are greater than 0.1 bar. 

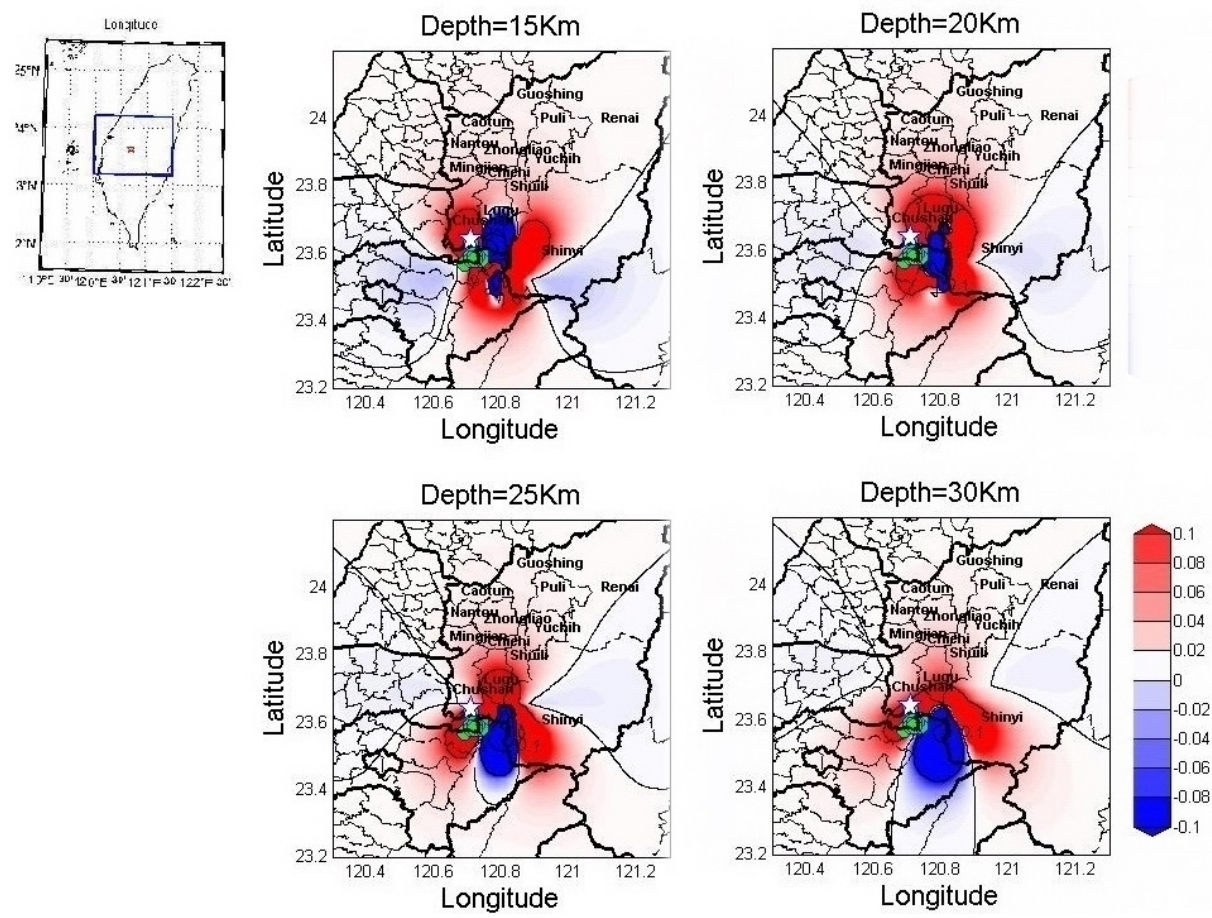

Figure 3. The $\triangle \mathrm{CFSs}$ of Chushan event varied with different depths from $15 \mathrm{~km}$ to $30 \mathrm{~km}$. The green points represent the earthquakes triggered by the Chushan event

Table 1. The parameters of those earthquakes applied in Figure 3 (Data from CWB)

\begin{tabular}{|c|c|c|c|c|}
\hline Date & Longitude & Latitude & Magnitude $\left(\mathrm{M}_{\mathrm{L}}\right)$ & Depth $(\mathrm{Km})$ \\
\hline $2017-11-17$ & 120.72 & 23.59 & 3.3 & 16.3 \\
\hline $2017-11-17$ & 120.71 & 23.63 & 2.8 & 14.2 \\
\hline $2017-11-21$ & 120.74 & 23.59 & 3.2 & 12.9 \\
\hline $2017-11-22$ & 120.74 & 23.59 & 2.9 & 12.5 \\
\hline $2017-11-22$ & 120.73 & 23.59 & 4.3 & 13.1 \\
\hline $2017-11-22$ & 120.72 & 23.59 & 3.1 & 17.4 \\
\hline $2017-11-22$ & 120.71 & 23.59 & 3.4 & 16.3 \\
\hline $2017-11-22$ & 120.74 & 23.59 & 3.3 & 13.1 \\
\hline $2017-11-22$ & 120.71 & 23.59 & 3.3 & 17.2 \\
\hline $2017-11-22$ & 120.71 & 23.59 & 2.9 & 16.5 \\
\hline $2017-11-22$ & 120.71 & 23.59 & 3.2 & 15.5 \\
\hline $2017-11-23$ & 120.71 & 23.59 & 3.3 & 15.5 \\
\hline $2017-11-23$ & 120.71 & 23.59 & 3.0 & 17.3 \\
\hline $2017-11-23$ & 120.71 & 23.59 & 5.0 & 16.4 \\
\hline $2017-11-23$ & 120.74 & 23.60 & 3.1 & 15.3 \\
\hline $2017-11-23$ & 120.74 & 23.60 & 3.9 & 14.0 \\
\hline $2017-11-24$ & 120.72 & 23.59 & 3.2 & 15.9 \\
\hline $2017-11-24$ & 120.71 & 23.59 & 3.2 & 16.0 \\
\hline $2017-11-24$ & 120.72 & 23.58 & 3.3 & 14.2 \\
\hline $2017-11-24$ & 120.74 & 23.58 & 3.1 & 14.9 \\
\hline $2017-11-24$ & 120.69 & 23.57 & 3.2 & 12.1 \\
\hline 2017-11-24 & 120.73 & 23.59 & 3.1 & 16.0 \\
\hline $2017-11-25$ & 120.72 & 23.59 & 3.3 & 15.8 \\
\hline $2017-11-25$ & 120.72 & 23.59 & 2.7 & 14.4 \\
\hline $2017-11-26$ & 120.71 & 23.58 & 3.6 & 15.6 \\
\hline $2017-11-27$ & 120.72 & 23.59 & 3.9 & 14.3 \\
\hline $2017-11-28$ & 120.72 & 23.58 & 5.6 & 15.2 \\
\hline $2017-11-28$ & 120.71 & 23.63 & 3.7 & 14.3 \\
\hline 2017-11-30 & 120.71 & 23.63 & 2.9 & 14.0 \\
\hline $2017-11-30$ & 120.71 & 23.63 & 3.9 & 13.4 \\
\hline
\end{tabular}




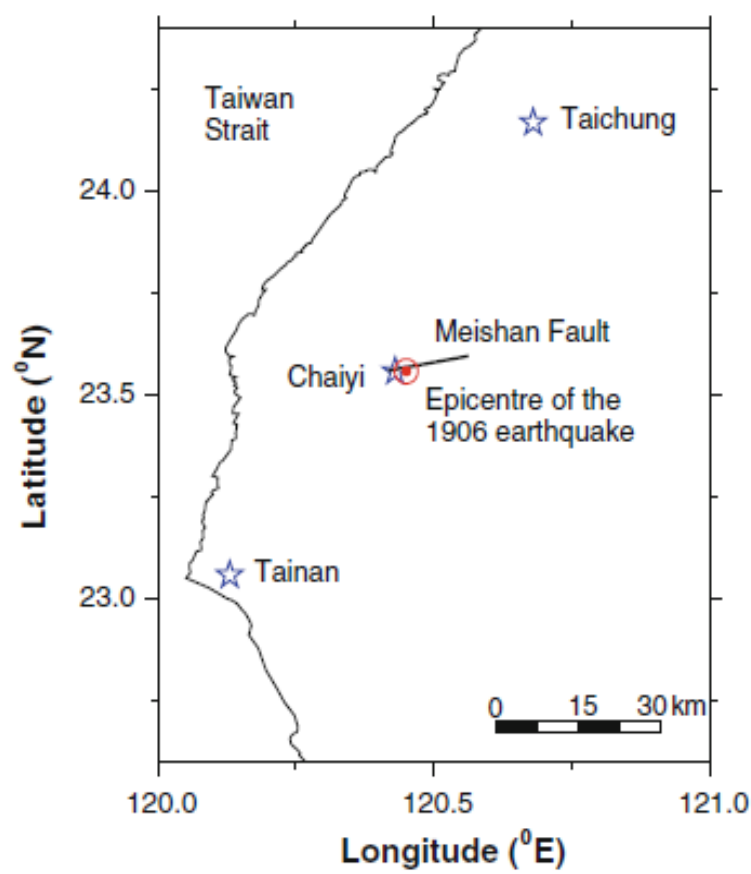

Figure 4. The locations of Meishan fault and the epicenter of the Meishan earthquake are represented as black line and star, respectively [20].

According to this result, it is reasonable to speculate these earthquakes may be triggered by the Chushan event and explain well why the depths of these earthquakes are below $15 \mathrm{~km}$. In addition, this result may indicate one fact that there highly intense background stresses may have been present in the regions prior to earthquakes that were triggered in them. Therefore, some stresses transformed from earthquakes may trigger the movement of active fault, causing destructive damages and serious disasters of people. One of the active faults in southwestern Taiwan, Meishan fault (in Figure 4), had caused large damages in central Taiwan. Last movement of the Meishan fault was on Mar. 17, 1906, indicating it hasn't moved over 110 years from now, thus the seismic hazards must be evaluated by an effective method precisely.

To evaluate the damages in Nantoucouty, Taiwan, the PGA and spectral intensities SIs are estimated as indexes in this research. Based on the past recording, we assume the magnitude of the potential Meishan earthquake is $M_{w}$ 7.1. Ueng [21] suggested that the parameters $T_{1} \sim T_{6}$ in (13 15) should be assumed as $0.1,0.6,0.6,1.6,1.6$ and 3 seconds applied to the earthquake. The different integration ranges correlate to the buildings with $1 \sim 6$ floors, 7 22 floors and taller than 22 floors. The PGA and SIa are demonstrated in Figure 5 and 6, respectively.

In Figure 5, the distribution of PGAs demonstrates the PGAs in Chushan and Mingjian townships exceed 500 gal and the maximum over 650 gal locates at the junctions of Nantou and Yunlin counties. These results mean that the buildings in Chushan and Mingjian townships may be destroyed seriously and great landslide which had been triggered by 1999 Chi-Chi earthquake may occur again at the same mountains located the junctions mentioned above. If the SIa which corresponds to the building with height about 1-6 floors exceeds $400 \mathrm{~cm} / \mathrm{s}^{2}$, the building's damage will be caused. In Figure 6, all the buildings below $18 \mathrm{~m}$ in Nantou county may be damaged especially at ChuShan and Mingjian townships and Nantou city when the Meishan earthquake is occurring. The distributions of SIv and SId are shown in Figure 7 and 8. Figure 9 demonstrates parts of Freeway 3 and Freeway 6 in the central Taiwan.

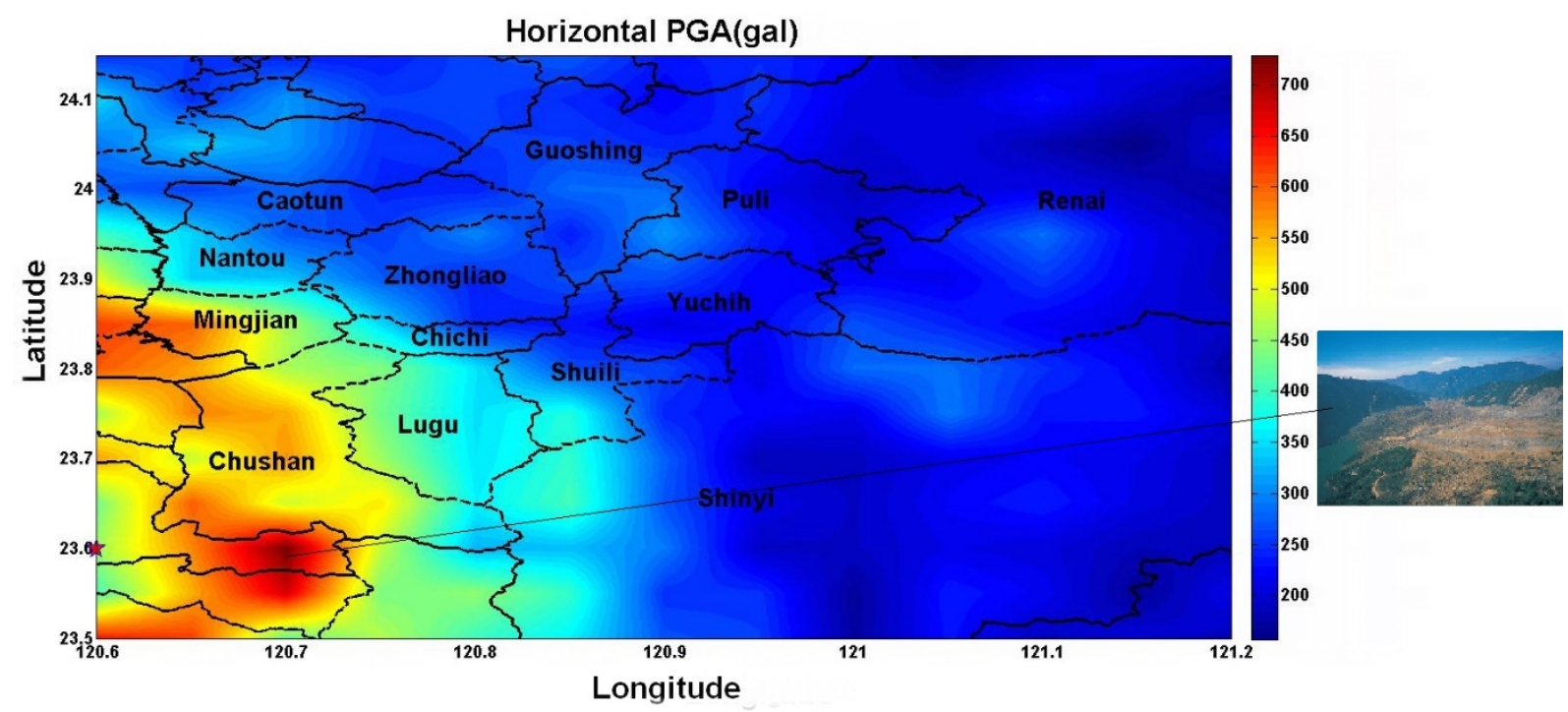

Figure 5. The estimated PGA distribution of Meishan earthquake in the central Taiwan. The landslide occurred at the junction of Nantou and Yunlin counties when the 1999 Chi-Chi earthquake happened. It is possible that the landslide may occur again when the Meishan earthquake happen. 


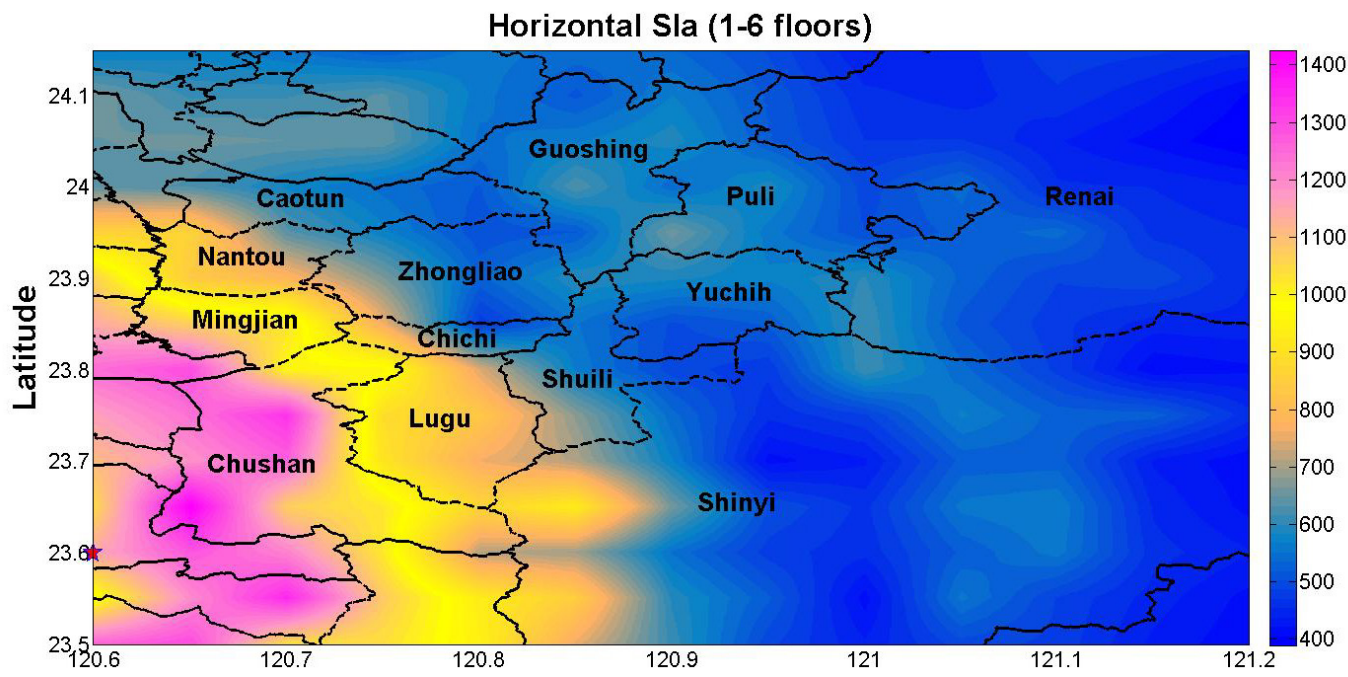

Figure 6. The SIa distribution of Meishan earthquake in the central Taiwan

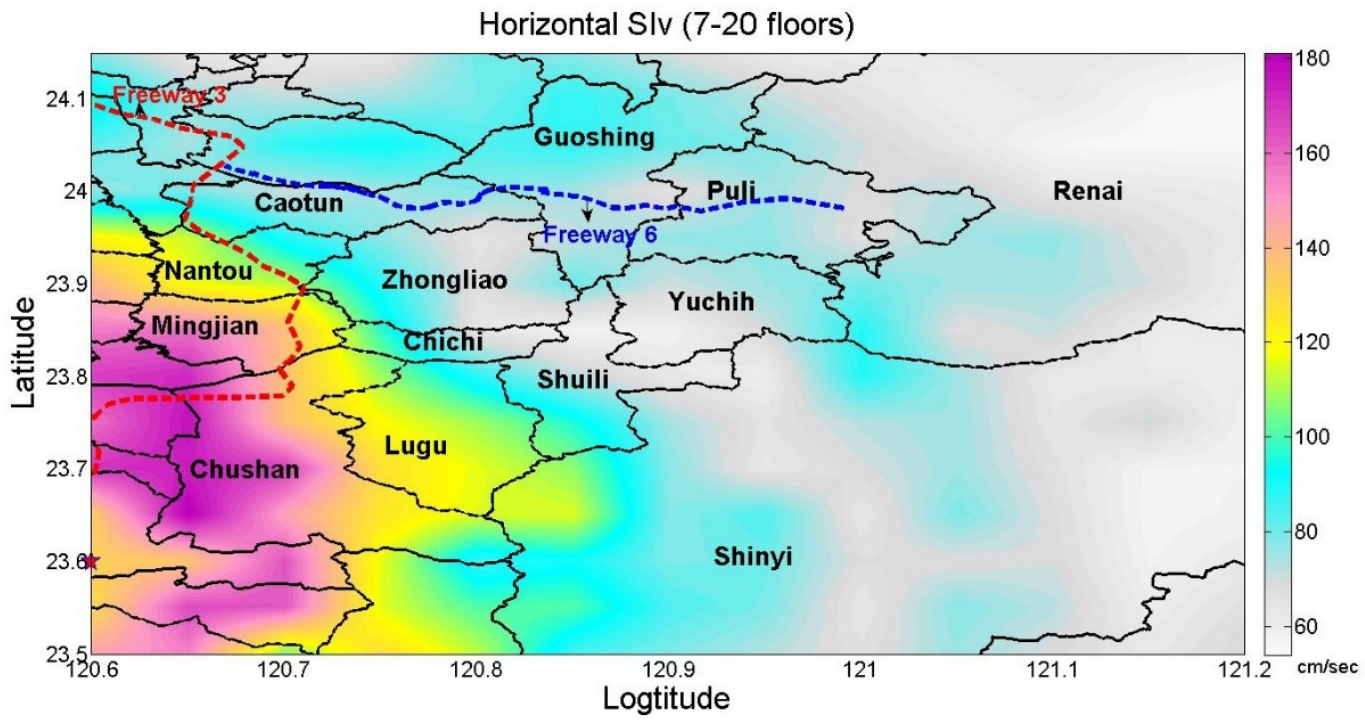

Figure 7. The SIv distribution of Meishan earthquake in the central Taiwan.

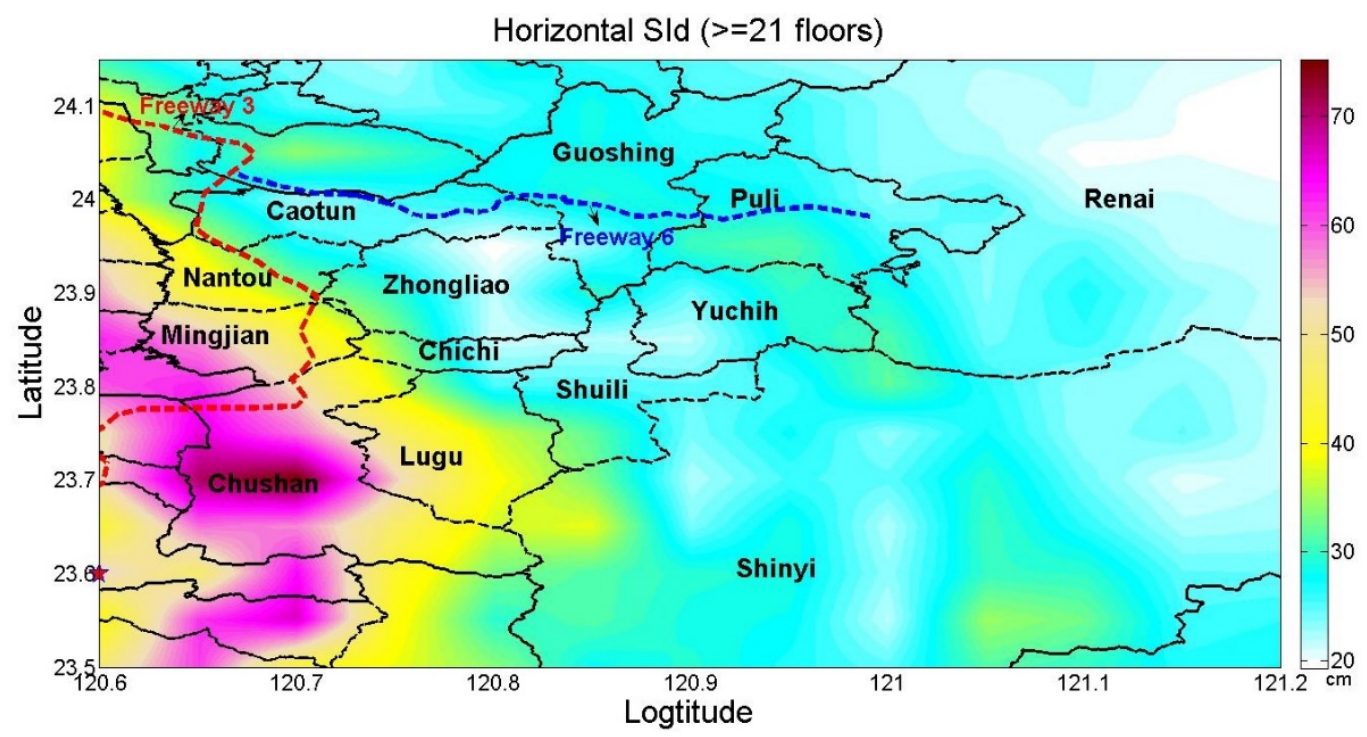

Figure 8. The SId distribution of Meishan earthquake in the central Taiwan. 


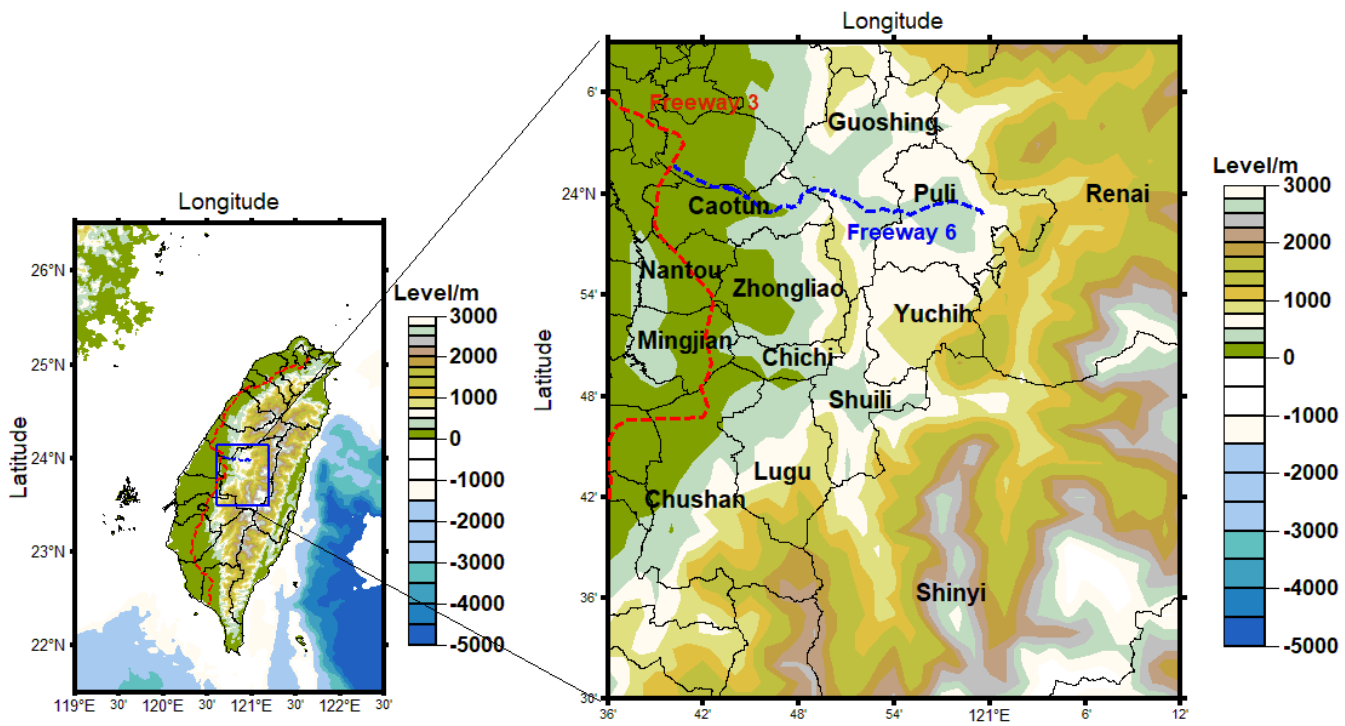

Figure 9. The locations of parts of Freeway 3 and Freeway 6 in the central Taiwan.

Based on the figure 7 , it is obvious that the building with 7-21 floors located at Nantou city, ChuShan and Mingjian townships may be damaged. Addition, the part of the freeway 3 (red dashed line in Figure 7 and 9) connecting ChuShan and Nantou may be heavily destroyed, so their maintenances and reinforcements are essential. The SId value can be treated as an index for measuring the risks ofbuilding higher than 21 floors. In Figure 8, the SId values along freeway 6 (blue dashed line in Figure 8 and 9) are higher than $4 \mathrm{~cm}$ and actually the heights of some parts of freeway 6 are over 21 floors in Guoshing town. It is worth noting that the freeway 6 is needed to pay attentions on the reinforcements to prevent the people from the earthquake disasters.

\section{Conclusions}

In this paper, the coulomb stress changes are applied to investigate the mainshock-aftershock relation and to survey the triggering mechanism of earthquake. According to the results derived from the $\triangle \mathrm{CFS}$, it shows that most of the aftershocks of Chushan event and the earthquake cluster in the southeast of Chushan event all nearly nucleate within the areas with positive $\triangle \mathrm{CFSs}$ greater than 0.1 bar. These subsequent earthquakes may be triggered by the transferred positive $\triangle$ CFSs due to the Chushan event. The results also reflect one fact that the central and southwestern regions of Taiwan may have accumulated highly intense background stresses under grounds, that is, if some positive $\triangle$ CFSs load down with it, the potential earthquakes will be caused. The probability of occurring large earthquake is increasing in these regions [20]. In addition, the seismic hazards due to the Meishan earthquake are estimated by the seismic spectrum intensities. Based on the results by PGA and SIs system, the higher values of PGA and SIs system are distributed around Nantou city, ChuShan and Mingjian townships, indicating the buildings in these townships may be destroyed seriously when the Meishan earthquake is occurring. The maintenances and reinforcements of the freeway 6 and 3, which are the major roads connecting to densely populated townships in Nantou county, have to be implemented carefully.

\section{REFERENCES}

[1] Y. M. Wu, C.H. Chang, L. J. Zhao, B. H. Shyu, Y. G. Chen, K. Sieh, J. P. Avouac. Seismic Tomography of Taiwan: Improved Constraints from A Dense Network of Strong Motion Stations. Journal of Geophysical Research, 112, B08312, 2007.

[2] R. A. Harris, R. W. Simpson, P. A. Reseanberg. Influence of Static Stress Changes on Earthquake Locations in Southern California. Nature, 375, 221-224, 1995.

[3] R. A. Harris, R. W. Simpson: Suppression of Large Earthquakes by Stress Shadows. A Comparison of Coulomb and Rate-and-State Failure. Journal of Geophysical Research, 103, 24439-24451, 1998.

[4] K. Takeshi, Y. Kakehi. Rupture Process of the 2001 Hyogo-ken Hokubu, Japan, Earthquake (Mw 5.2) and Comparison between the Aftershock Cctivity and the Static Stress Changes. Bulletin of Seismological Society of America, 95, 145-158, 2005.

[5] A. Ganas, Z. Roumelioti, K. Chousianitis. Static Stress Transfer from the May 20, 2012, M 6.1 Emilia-Romagna (Northern Italy) Earthquake Using ACo-Seismic Slip Distribution Model. Annals of Geophysics, 55, 655-662, 2012. 
[6] C. J. Xu, J. Wang, Z. Li, J. Dummond. Applying the Coulomb Failure Function with An Optimally Oriented Plane to the $2008 \mathrm{Mw} 7.9$ Wenchuan Earthquake Triggering. Tectonophysics, 491, 119-126, 2010.

[7] T. Sato, S. Hiratsuka, J. Mori. Coulomb Stress Change for the Normal-Fault Aftershocks Triggered Near the Japan Trench by the $2011 \mathrm{Mw} 9.0$ Tohoku-Oki Earthquake. Earth Planets Space, 64, 1239-1243, 2010.

[8] B.Y. Liao, H. C. Huang. Coulomb Stress Changes and Seismicity in Central Taiwan due to the Nantou Blind-Thrust Earthquakes in 2013. Journal of Asian Earth Sciences, 124(1), 169-180, 2016.

[9] S. Wen, Y. L. Yeh, Y. Z. Chang, C. H. Chen. The Seismogenic Process of the 2016 Meinong Earthquake, Southwest Taiwan. Terrestrial, Atmospheric and Oceanic Sciences, 28, 651-662, 2017.

[10] S. Li, S. Wdowinski, Y. J. Hsu, J. B. H. Shyu. Earthquake Interactions in Central Taiwan: Probing Coulomb Stress Effects due to ML $\geq 5.5$ Earthquakes from 1900 to 2017 . Journal of Geophysical Research: Solid Earth, 125, JB019010, 2020.

[11] B. Y. Liao, C. N. Liu, T. W. Sheu, Y. T. Yeh. Earthquake Hazard in Central Taiwan Evaluated Using the Potentially Successive 2013 Nantou Taiwan Earthquake Sequences. Geomatics, Natural Hazards and Risk, 11(1), 678-697, 2020.

[12] B. Y. Liao. Evaluating the Seismic Hazards by Chang-Hua Fault at Nantou County, Taiwan and Disaster Resistant Strategy. IOP Conf Ser: Earth Environ Sci, 576, 012003, 2020 .

[13] N.-P. Victor, A. Jiménez, \& Á. Corral. No Significant
Effect of Coulomb Stress on the Gutenberg-Richter Law after the Landers Earthquake. Sci Rep 10, 2901, 2020

[14] X.Lin, R.Chu, \& X.Zeng. Rupture processes and Coulomb stress changes of the $2017 \mathrm{Mw} 6.5$ Jiuzhaigou and $2013 \mathrm{Mw}$ 6.6 Lushan earthquakes. Earth Planets Space 71, 81, 2019.

[15] M. Cocco, J.R. Rice. Pore pressure and poroelasticity effects in Coulomb stress analysis of earthquake interactions. J. Geophys Res. B2 2030, 107, 2002.

[16] A.Ganas, A.Gosar, G.Drakatos. Static Stress Changes due to the 1998 and 2004 Krn Mountain (Slovenia) Earthquakes and Implications for Future Seismicity. Natural Hazards and Earth System Science, 8, 59-66, 2008.

[17] D. Weatherley. Coulomb Stress Changes due to Queensland Earthquakes and the Implications for Seismic Risk Assessment. Earthquake Engineering in Australia, 1, 145-150, 2006.

[18] G. M. Atkinson, D. M. Boore. Evaluation of Models for Earthquake Source Spectra in Eastern North America. Bulletin of Seismological Society of America, 88,917-934, 1998.

[19] K. Sarkarinejad, S. Ansari. The Coulomb Stress Changes and Seismicity Rate due to the $1990 \mathrm{Mw} 7.3$ Rudbar Earthquake. Bulletin of Seismological Society of America, 104, 2943-2952, 2014.

[20] J. P. Wang, D. Huang, S. C. Chang. Assessment of seismic hazard associated with the Meishan fault in central Taiwan. Bulletin of Engineering Geology and the Environment, 72 (2), 249-256, 2013.

[21] Y. S. Ueong. A study on feasibility of SI for identification of earthquake damages in Taiwan. Soil Dynamics and Earthquake Engineering, 29, 185-193, 2009. 